\title{
Analisa Pemeringkatan Portal Website Universitas Sam Ratulangi Manado Menggunakan Linear Weightage Model \\ James P. Montolalu ${ }^{1)}$, Yaulie D. Y. Rindengan ${ }^{2)}$, Stanley Karouw ${ }^{3)}$ \\ Program Studi Teknik Informatika, Fakultas Teknik, Universitas Sam Ratulangi \\ 13021106048@unsrat.student.ac.id ${ }^{1)}$,rindengan@unsrat.ac.id²), stanley.karouw@unsrat.ac.id ${ }^{3)}$
}

\begin{abstract}
Abstrak - Universitas Sam Ratulangi (UNSRAT) menduduki peringkat 50 di situs webometrics dan peringkat 67 di situs 4 ICU tentunya ingin berupaya agar bisa menaikkan peringkat dari website UNSRAT tersebut. Penelitian ini bertujuan untuk menganalisa faktor-faktor yang dapat diupayakan agar dapat menaikkan peringkat dari website UNSRAT. Metode yang digunakan dalam pengambilan data website yaitu Automated Website Evaluation. Kriteria penilaian yang digunakan adalah load time, page rank, broken link, markup validation, css validation, backlinks, rich files. Kemudian dilakukan pemeringkatan menggunakan metode Linear Weightage Model. Hasil pemeringkatan LWM ini nantinya akan dibandingkan dengan peringkat webometrics dan 4ICU. Hasil penelitian dapat menajadi saran dan panduan bagi pihak UNSRAT agar dapat memperbaiki kualitas website-nya serta meningkatkan peringkat website-nya.
\end{abstract}

Kata kunci : Pemeringkatan Web, UNSRAT, webometrics, 4ICU, Automated Website Evaluation, Linear Weightage Model

\section{PENDAHULUAN}

Universitas Sam Ratulangi (UNSRAT) merupakan salah satu perguruan tinggi negeri yang berada di Sulawesi Utara, tepatnya di Kota Manado. Perguruan tinggi negeri di Indonesia berlombalomba untuk memperbaiki kualitas website-nya untuk mengejar predikat kampus unggulan yang ditunjukkan melalui teknologi informasi dan komunikasi, terlebih lagi untuk masuk pada database penilai universitas dunia, diantaranya yaitu Webometric [1] dan 4 International Colleges \& Universities atau 4ICU [2] Ketika penelitian ini dilaksanakan, peringkat web dari UNSRAT yaitu www.unsrat.ac.id berdasarkan webometric berada di peringkat ke 50 di Indonesia dan peringkat ke 4227 di dunia. Sedangkan berdasarkan situs penilai universitas $4 \mathrm{icu}$, UNSRAT berada di peringkat ke 67 se-Indonesia. 2

Webometrics merupakan ranking perguruan tinggi yang dilakukan oleh Cybermetrics Lab.
Webometric memulai pemeringkatan website perguruan tinggi pada tahun 2004 dengan menggunakan gabungan indikator yang disebut WR, antara lain: jumlah halaman website $(25 \%)$, jumah file pdf, ps, doc dan ppt (12.5\%), jumlah publikasi yang masuk di Google Scholar Database (12.5\%) dan jumlah external inlinks (50\%) [3]. 4 International Colleges \& Universities (4ICU) merupakan direktori dan ranking perguruan tinggi di dunia yang dibuat oleh web 4icu.org. 4ICU melakukan penilaian berdasarkan kepopuleran situs yang dimiliki oleh 11.307 perguruan tinggi di seluruh dunia yang telah terakreditasi, komponen penilaian yang digunakan 4ICU adalah Google Page Rank, Alexa Traffic Rank, dan Majestic SEO. adalah:

Adapun batasan masalah pada penelitian ini 1. Kriteria penilaian yang digunakan adalah load time, page rank, broken link, markup validation, css validation, backlinks, dan rich files.

2. Pengambilan data untuk keperluan pemeringkatan portal website resmi UNSRAT menggunakan Metode Automated Website Evaluation .

3.Perankingan portal website resmi UNSRAT menggunakan Metode Linear Weightage Model.

4. Data Webometric dan 4ICU yang diambil sebagai pembanding adalah data website resmi perguruan tinggi di Indonesia pada periode pertengahan tahun 2017 dan awal tahun 2018.

5. Data yang disampel adalah data website resmi universitas lain yang peringkatnya ada yang di atas UNSRAT, setara seperti UNSRAT, dan di bawah UNSRAT.

\section{LANDASAN TEORI}

A. Pemeringkatan Website Universitas

Menurut Badan Pengembangan dan Pembinaan Bahasa Kemendikbud RI, pemeringkatan adalah proses menyusun urutan berdasarkan tolok ukur tertentu. Kedudukan dalam urutan itu disebut peringkat atau rank.

Website merupakan kumpulan halaman web yang saling terhubung dari file-filenya saling terkait. Web terdiri dari page atau halaman dan kumpulan halaman yang dinamakan homepage. Menurut Peraturan Pemerintah RI Nomor 4 Pasal 1 Tahun 
2014 tentang Penyelenggaraan Pendidikan Tinggi dan Pengelolaan Perguruan Tinggi menerangkan bahwa Universitas adalah Perguruan Tinggi yang menyelenggarakan pendidikan akademik dan dapat menyelenggarakan pendidikan vokasi dalam berbagai rumpun ilmu pengetahuan dan/atau teknologi dan jika memenuhi syarat, Universitas dapat menyelenggarakan pendidikan profesi.

Dari penjelasan di atas dapat disimpulkan bahwa pemeringkatan website universitas adalah proses penyusunan urutan atau peringkat perguruan tinggi yang menyelenggarakan pendidikan akademik dan dapat menyelenggarakan pendidikan vokasi dalam berbagai rumpun ilmu pengetahuan dan/atau teknologi berdasarkan tolok ukur kumpulan halaman web yang saling terhubung dan file-file yang saling terkait dengan cara mengevaluasi website menggunakan tools tertentu . Situs-situs yang biasa digunakan untuk melakukan pemeringkatan website ini antara lain Google Page Rank, Alexa Rank, Webometrics, 4ICU, dan lain sebagainya.

\section{B. Metode Automated Website Evaluation}

Metode Automated Website Evaluation [4] ini merupakan metode yang digunakan dalam penelitian kali ini untuk pengambilan data. Sedangkan metode Linear Weightage Model digunakan untuk melakukan pemeringkatan website dengan cara menormalisasikan nilai-nilai yang telah didapat dari proses pengambilan data. Evaluasi berarti memeriksa dan menilai dengan hati-hati berdasarkan parameter yang ditentukan. Evaluasi website dapat dilakukan melalui pendekatan sudut pandang pengguna (user), dari sudut pandang website designer/administrator, atau dari sudut pandang keduanya. Metode automated website evaluation bekerja dengan memeriksa kode sumber dari halaman web dengan menggunakan suatu "alat" untuk menentukan kompatibilitas website dengan pedoman yang ditetapkan, pedoman ini dapat mencakup pedoman atau panduan yang diterima dalam komunitas tertentu dan diterima secara universal. [5]

Ada banyak kriteria untuk mengevaluasi sebuah situs web. Diantaranya : usability, authority, currency, objectivity, coverage, performance, traffic ranking, link popularity, functionality, accessibility, security, design patterns, HTML syntax analysis, and browser compatibility.

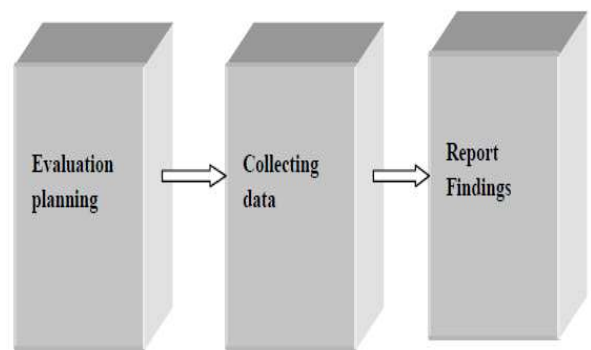

Gambar 1. Proses evaluasi website.[5]

Ada banyak alat yang tersedia untuk melakukan evaluasi terhadap aksesbilitas suatu situs web. Dari yang bisa digunakan untuk memeriksa CSS, memeriksa broken link, gambar dan lain sebagainya. Alat-alat ini dapat secara otomatis mengevaluasi suatu situs web.

\section{Metode Linear Weightage Model}

Ada banyak metode yang bisa digunakan untuk melakukan pemeringkatan suatu website antara lain : entrophy, promthee, factor analys, vikor, elektre, Linear Weightage Model, Multicriteria Decision Analysis, Thurstone, Inbound Outbound, dan lain-lain. Dalam penelitian ini penulis menggunakan metode pemeringkatan Linear Weightage Model. Metode ini pada dasarnya digunakan untuk normalisasi nilai. Langkah pertama dalam evaluasi website adalah menentukan kriteria apa saja yang akan digunakan untuk menilai website. Kriteria-kriteria yang dihasilkan diidentifikasi untuk dibedakan menjadi threshold minimum dan maximum. Kriteria dikelompokkan, apabila nilai kriteria bertipe "nilai besar lebih baik" maka dimasukkan dalam kelompok threshold minimum, dan apabila nilai kriteria bertipe "nilai kecil lebih baik" maka dimasukkan dalam kelompok threshold maximum. [6]

Persamaan yang digunakan sebagai berikut

$$
\begin{aligned}
& w s_{\max }=\frac{\max -\text { website }}{\max -\min }[6] \\
& w s_{\min }=\frac{\text { website }-\min }{\max -\min }[6]
\end{aligned}
$$

Keterangan:

$$
\begin{aligned}
& w S_{\max }=\text { nilai kriteria bertipe threshold maximum } \\
& w S_{\min }=\text { nilai kriteria bertipe threshold minimum } \\
& \max =\text { nilai tertinggi pada kriteria yang sama } \\
& \min =\text { nilai terendah pada kriteria yang sama } \\
& \text { website = nilai yang akan dinormalisasi }
\end{aligned}
$$




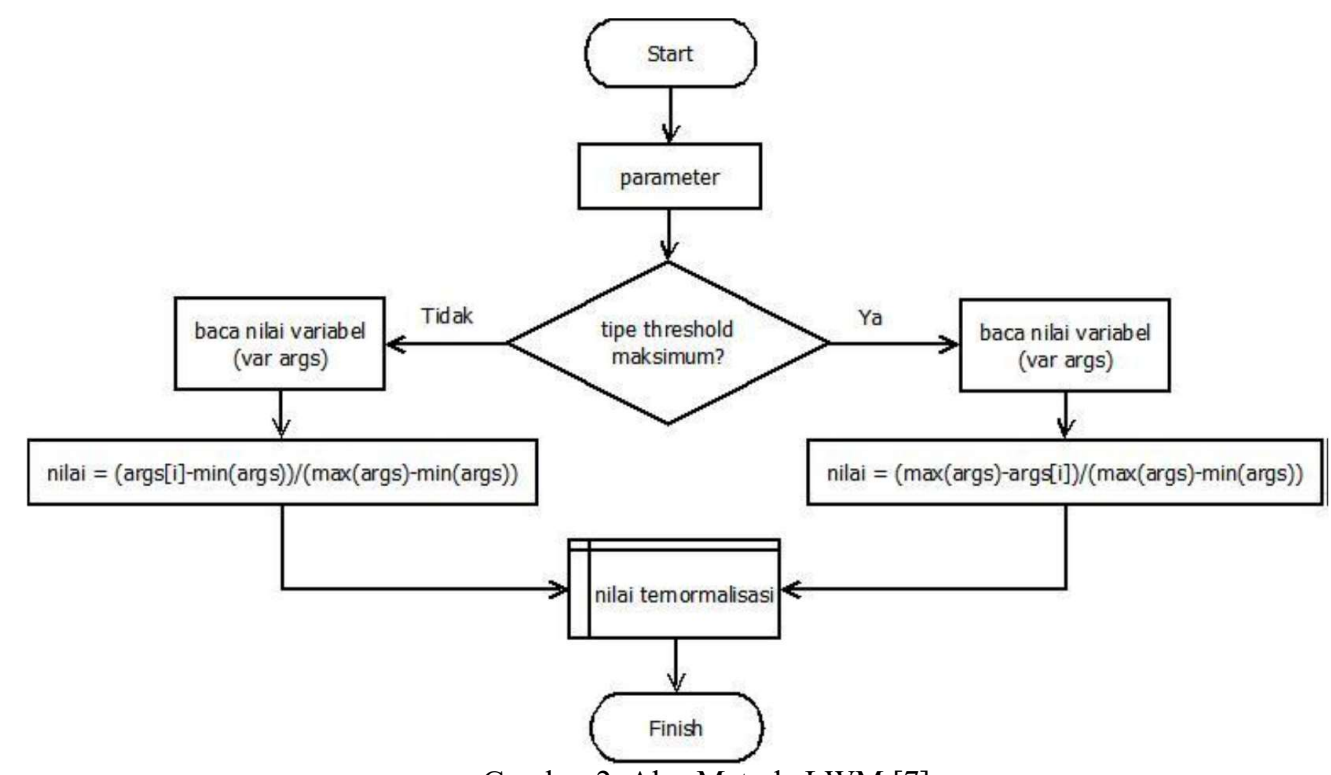

Gambar 2. Alur Metode LWM [7]

D. Pengertian Webometrics dan 4ICU

Webometrics digunakan sebagai alat pengukur World Wide Web (www) atau situs web untuk dapat mengetahui jumlah hyperlink, jenis hyperlink, struktur website, dan pola penggunaannya. Definisi dari webometrics adalah "studi tentang aspek-aspek kuantitatif dari konstruksi dan penggunaan sumber daya informasi, struktur dan teknologi pada gambar web melalui pendekatan bibliometrik dan informetric".[8] Sebagai alat ukur (webometrics) sudah mendapat pengakuan dunia termasuk di Indonesia (sekalipun masih ada yang meragukan tingkat validitasinya). Peringkat webometrics pertama kali diluncurkan pada tahun 2004 oleh Laboratorium Cybermetric milik The Consejo Superior de Investigaciones Cientificas (CSIC). CSIC merupakan lembaga penelitian terbesar di Spantol. Secara periodic peringkat webometric akan diterbitkan setiap 6 bulan sekali pada bulan Januari dan Juli. Peringkat ini mengukur lebih dari 16.000 lembaga pendidikan tinggi di seluruh dunia yang terdaftar dalam direktori. Peringkat webometrics dapat diakses dengan cara mudah dan terbuka pada http://www.webometrics.info/ .

4ICU adalah suatu search engine dan direktori yang melakukan penilaian berdasarkan kepopuleran situs yang dimiliki oleh 11.000 pergurutan tinggi di seluruh dunia yang telah terakreditasi dan tersebar dalam 200 negara.

\section{E. Pengujian Spearman}

Uji Spearman merupakan metode korelasi yang dikemukakan oleh Carl Spearman pada tahun 1904.[8] Metode ini diperlukan untuk mengukur keeratan hubungan antara dua variabel. Kedua variabel itu tidak harus mengikuti distribusi normal dan kondisi variabel tidak diketahui sama. Korelasi rank dipergunakan apabila pengukuran kuantitatif secara eksak tidak mungkin dilakukan. Data kedua variabel berpasangan, misalnya mengukur tingkat moral, tingkat kesenangan, tingkat motivasi dan sebagainya

$$
\rho=1-\frac{6 \sum b i^{2}}{n\left(n^{2}-1\right)} \text { [8] }
$$

Dimana :

$\rho=$ koefisien korelasi Spearman-rank

bi $=$ perbedaan setiap pasang rank

$\mathrm{n}=$ jumlah pasangan sampel

Setelah ditemukan hasilnya, maka langkah selanjutnya yaitu membandingkan nilai probabilitas dengan nilai tabel koefisien Spearman. Dalam pengujian hipotesis jika nilai $\rho$ hitung $<-\rho$ tabel dan $\rho$ hitung $>\rho$ tabel maka $\mathrm{H} 0$ ditolak dan Ha diterima. Jika $\rho$ hitung $>-\rho$ tabel dan $\rho$ hitung $<\rho$ tabel maka H0 diterima dan Ha ditolak. 


\section{METODOLOGI PENELITIAN}

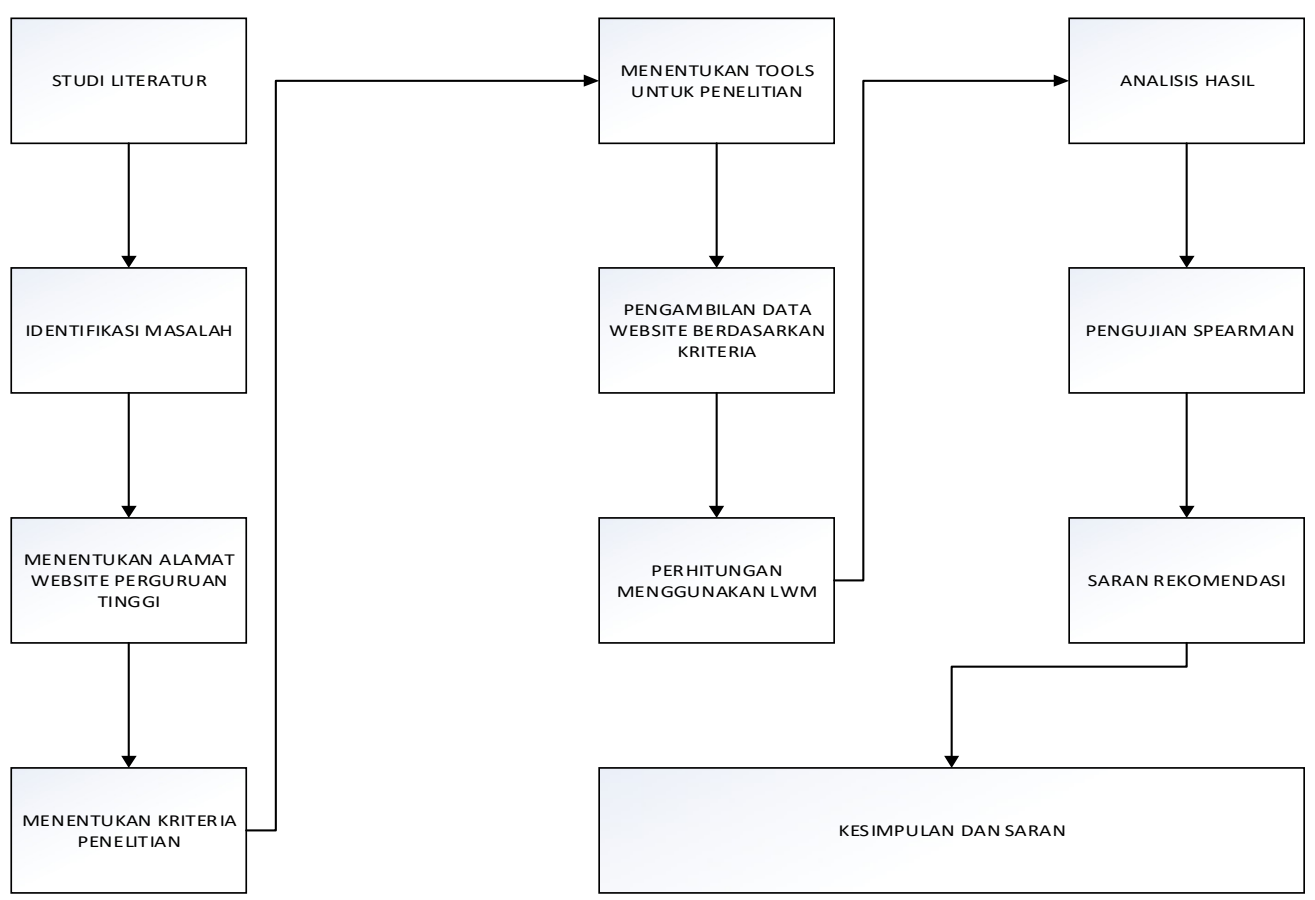

Gambar 3. Alur penelitian

A. Studi Literatur

Studi literatur adalah mencari referensi teori yang relevan dengan kasus atau permasalahan yang ditemukan. Dilakukan studi literatur pada buku, jurnal, artikel laporan penelitian, dan situs-situs di internet yang berkaitan tentang metode pemeringkatan web. Output dari studi literatur ini adalah terkoleksinya referensi yang relevan dengan identifikasi masalah.

B. Identifikasi Masalah

Identifikasi masalah yang didapat yaitu:

1. Website UNSRAT berada di ranking $20 \mathrm{ke}$ bawah yaitu menurut 4ICU rangking 67 (Juli 2017), rangking 52 (Januari 2018) dan menurut webometrics rangking 50 (Juli 2017), rangking 85 (Januari 2018) .

2. Belum ditemukan adanya data-data terperinci terkait website UNSRAT khususnya.

C. Menentukan Alamat Website Perguruan Tinggi Alamat website yang dijadikan sebagai sampel dalam penelitian ini yaitu 5 peringkat website yang setara website UNSRAT, 5 peringkat website yang diatas UNSRAT, 5 peringkat website yang di bawah UNSRAT untuk versi Juli 2017 dan 5 peringkat website teratas , 5 peringkat website di atas UNSRAT , 5 peringkat website di bawah UNSRAT serta website UNSRAT untuk versi Januari 2018.

D. Menentukan Kriteria Penelitian
Kriteria yang digunakan dalam penelitian ini adalah load time, page rank, broken link, markup validation, css validation, backlinks, dan rich files.

E. Menentukan tools untuk penelitian Untuk pengumpulan data, peneliti menggunakan beberapa instrument penelitian yang berupa online checker. Online checker adalah fasilitas atau software yang disediakan oleh beberapa situs website untuk mengukur komponen-komponen dari suatu website secara online. Alat ukur yang digunakan merupakan alat ukur-alat ukur yang sudah teruji dan dapat dipertanggungjawabkan. Jadi, untuk melakukan pengukuran atau pengambilan data, maka peneliti harus terhubung ke internet.

F. Pengambilan data website berdasarkan kriteria Pengambilan data dilakukan sebanyak 15 kali untuk setiap kriteria penilaian website. Hasilnya selanjutnya akan dirata-rata secara terpisah untuk setiap instrument sehingga akan didapati tujuh buah data sesuai dengan jumlah variabel penelitian yang digunakan pada masing-masing universitas yang diteliti.

\section{G. Perhitungan menggunakan LWM}

Setelah diperoleh data penilaian website dengan online checker berdasarkan masing-masing kriteria dengan menggunakan metode Automated Website Evaluation, selanjutnya dilakukan perhitungan menggunakan metode LWM. Sebelum data 
dianalisis, bobot setiap kriteria ditentukan terlebih dulu.

H. Pengujian Spearman

Dalam korelasi Spearman-rank, sumber data untuk kedua variabel yang akan dikonversikan dapat berasal dari sumber yang tidak sama, jenis data yang dikorelasikan adalah data ordinal serta data dari kedua variabel tidak harus membentuk distribusi normal.

\section{HASIL DAN PEMBAHASAN}

\section{A. Pengumpulan data}

Hasil pengambilan data setelah menggunakan tools penelitian yang sudah dirata-raakan.

TABEL I. Nilai rata-rata dari data webometrics untuk data Januari 2018

TABEL II. Nilai rata-rata dari data $4 I C U$ untuk data Januari 2018

\section{B. Analisa LWM}

Data yang telah terkumpul kemudian dinormalisasi dengan menggunakan metode Linear Weigthage Model untuk menentukan peringkat baru. Hasil dari perhitungan metode Linear Weigthage Model ini kemudian akan dibandingkan dengan hasil pemeringkatan webometrics dan 4ICU menggunakan pengujian spearmen.

Data webometrics

TABEL III. Hasil perhitungan ranking menggunakan metode LWM untuk data webometrics (Januari 2018)

Data 4ICU

TABEL IV. Hasil perhitungan ranking menggunakan metode LWM untuk data 4ICU (Januari 2018)

keterangan :

$J=$ jumlah

$w=$ bobot

$R=$ ranking

C. Spearman Test

Spearman test digunakan untuk membandingkan hasil perangkingan yang dilakukan oleh webometrics dan 4ICU dengan hasil perangkingan menggunakan metode Linear Weightage Model.

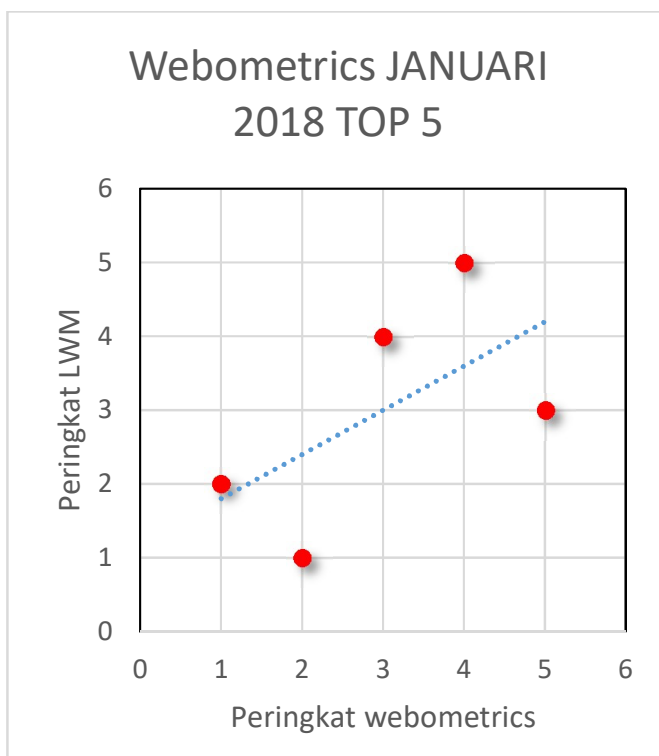

Gambar 4. Grafik Spearman Webometrics Januari 2018 TOP 5
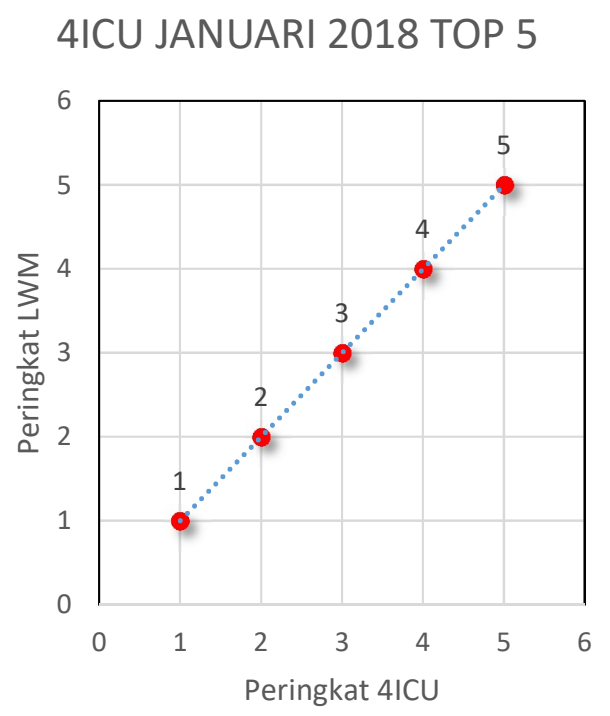

Gambar 5.Grafik Spearman 4ICU Januari 2018 TOP 5

\section{PENUTUP}

A. Kesimpulan

Berdasarkan hasil pengolahan data penelitian dapat diambil kesimpulan bahwa:

a. Hasil evaluasi pemeringkatan website resmi UNSRAT menggunakan tools Automated Website Evaluation menunjukkan hasil bahwa :

- $\quad$ Load time UNSRAT $=8.715 \mathrm{~s}$ (Juli 2017) dan 8.469 s (Januari 2018)

- $\quad$ Page rank UNSRAT =6 (Juli 2017 dan Januari 2018) 
- $\quad$ Broken link UNSRAT $=17.8$ (Juli 2017) dan 44.533 (Januari 2018)

- Markup validation UNSRAT = 155.933 (Juli 2017) dan 163.333 (Januari 2018)

- $\quad$ CSS validation UNSRAT $=66.2(\mathrm{Juli}$ 2017) dan 10 (Januari 2018)

- $\quad$ Backlinks UNSRAT $=1590.333$ (Juli 2017) dan 1596 (Januari 2018)

- $\quad$ Rich files UNSRAT $=19495.47$ (Juli 2017) dan 25213.333 (Januari 2018)

b. Hasil evaluasi pemeringkatan website resmi UNSRAT menggunakan Metode Pemeringkatan Linear Weightage Model menunjukkan hasil :

- Pemeringkatan webometrics (Juli 2017) dengan LWM yang sebelumnya rangking 8 dari 15 menjadi rangking 4 dari 15

- Pemeringkatan 4ICU (Juli 2017) dengan LWM yang sebelumnya rangking 8 dari 15 menjadi rangking 2 dari 15

- Pemeringkatan webometrics (Januari 2018) dengan LWM yang sebelumnya rangking 6 dari 11 menjadi rangking 2 dari 11

- Pemeringkatan 4ICU (Januari 2018) dengan LWM yang sebelumnya rangking 6 dari 11 menjadi rangking 1 dari 11

c. Berdasarkan hasil pengujian dan grafik korelasi spearman menyatakan bahwa :

- Tidak terdapat hubungan antara hasil pemeringkatan webometrics Juli 2017 dengan LWM

- Tidak terdapat hubungan antara hasil pemeringkatan 4ICU Juli 2017 dengan LWM

- Tidak terdapat hubungan antara hasil pemeringkatan webometrics Januari 2018 TOP 5dengan LWM

- Terdapat hubungan antara hasil pemeringkatan 4ICU Januari 2018 TOP 5 dengan LWM

- Tidak terdapat hubungan antara hasil pemeringkatan webometrics Januari 2018 dengan LWM

- $\quad$ Tidak terdapat hubungan antara hasil pemeringkatan 4ICU Januari 2018 dengan LWM

d. Berdasarkan hasil evaluasi pemeringkatan website resmi UNSRAT menggunakan metode LWM dapat disimpulkan bahwa website resmi UNSRAT mengalami peningkatan dari pemeringkatan webometrics / 4ICU dibandingkan dengan pemeringkatan LWM. Dikarenakan berdasarkan pengujian spearman tidak terdapat kesesuaian antara pemeringkatan webometrics / 4ICU dengan LWM maka pemeringkatan LWM ini hanya bisa dijadikan pemeringkatan secara internal dari pihak UPT TIK UNSRAT.

B. Saran

a. Kecepatan koneksi internet dapat mempengaruhi proses pengambilan data, maka bagi calon peneliti selanjutnya sebaiknya menggunakan koneksi internet yang baik dan stabil.

b. Bagi peneliti selanjutnya dapat menambahkan jumlah sampel yang digunakan dalam penelitian serta dapat menggunakan metode pemeringkatan lain untuk mendapatkan peringkat website universitas.

\section{DAFTAR REFERENSI}

[1] Webometrics, http://www.webometrics.info

[2] 4 International Colleges \& Universities atau 4ICU, http://www.4icu.org

[3] Dewi Wulandari, Rangking Webometrics untuk Universitas di Indonesia Menggunakan Metode Pembobotan Entropy dan Metode Pemeringkatan Promethee. Yogyakarta, 2016.

[4] Sukhpal Kaur., "An Automated Tool for Web Site Evaluation", International Journal of Computer Science and Information Technologies, 2011, vol.3.4310-4313.

[5] Melody Y. Ivory., Aline Chevalier., A Study of Automated Web Site Evaluation Tools. Washington, Oktober 2002.

[6] Dominic ., Handaru Jati , "University Website Quality Comparison by Using Non-Parametic Statistical Test : a Case Study from Malaysia", Int. J. Operational Research, 2013, vol.16 No.3.

[7] Sugiyono. Statistik Non Parametris. Bandung: Alfabeta. 2009.

[8] Moh. Miftakhur Rokhman, Analisis Usability Website Universitas di Indonesia dengan Metode Pembobotan Entropi serta Metode Perangkingan Topsis dan Kaitannya dengan Peringkat Rilis Webometrics. Yogyakarta , 2014.

[9] Brajnik, G. (2002) 'Quality models based on automatic web testing', CHI Workshop, Minneapolis,ACM.

[10] Thomas Tiedtke., Christian Martin ., Noberth Gerth. 2002. A Tool for Automated Website Usability Analysis. Augsburg.

[11] Widya Silfianti ., Mirma Y. Firdausi ., Hanum P. Permatasari. 2010. Model Pemeringkatan Website Pemerintah Daerah di Indonesia. Bandung. 


\section{SEKILAS TENTANG PENULIS}

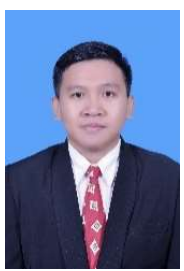

James Philip Montolalu, lahir di Jakarta, Provinsi DKI Jakarta 26 Februari 1995. Penulis merupakan anak ke-2 dari 3 bersaudara. Penulis mulai menempuh pendidikan di Sekolah Dasar BPS\&K 7 Bekasi (2001 - 2007). Penulis lalu melanjutkan ke Sekolah Menengah Pertama Pax Ecclesia Bekasi (2007 - 2010) dan Sekolah Menengah Atas Patriot Bekasi (2010-2013). Pada tahun 2013 penulis melanjutkan studi ke Perguruan Tinggi Negeri di UNSRAT Manado dengan mengambil Program Studi S-1 Teknik Informatika di Jurusan Elektro Fakultas Teknik. Kemudian, pada bulan Juni 2017 penulis membuat skripsi demi memenuhi syarat Sarjana (S1) dengan penelitian berjudul "Analisa Pemeringkatan Website Universitas Sam Ratulangi Menggunakan Automated Website Evaluation dan Linear Weightage Model" dengan pembimbing I oleh Yaulie Deo. Y. Rindengan, ST, MM, MSc., MTI., dan pembimbing II oleh Stanley Karouw, ST.,MTI. Sehingga pada tanggal 8 Juni 2018 penulis resmi lulus di Teknik Informatika Universitas Sam Ratulangi dan menyandang gelar Sarjana Komputer. 
TABEL I. Nilai rata-rata dari data webometrics untuk data Januari 2018

\begin{tabular}{|c|c|c|c|c|c|c|c|}
\hline situs & LT & PR & BL & MV & $\mathrm{CV}$ & B & RF \\
\hline www.ui.ac.id & 11.609 & 7 & 344.267 & 59 & 481.133 & 17799 & 474735.867 \\
\hline ugm.ac.id & 11.747 & 7 & 51.267 & 46.867 & 6 & 20255 & 367405.667 \\
\hline www.itb.ac.id & 30.586 & 9 & 26.333 & 19 & 6 & 9834 & 49839.133 \\
\hline ipb.ac.id & 23.984 & 6 & 123.867 & 285.4 & 37 & 12828 & 215875.667 \\
\hline www.unsyiah.ac.id & 9.378 & 7 & 48.4 & 125 & 0 & 3635 & 29850.6 \\
\hline www.umuslim.ac.id & 5.528 & 3 & 19.933 & 19.867 & 28.6 & 513 & 1168.867 \\
\hline www.esaunggul.ac.id & 19.965 & 5 & 18.533 & 57 & 126 & 2956.333 & 72578.667 \\
\hline ipdn.ac.id & 4.830 & 5 & 27.933 & 35 & 83 & 769 & 1328.133 \\
\hline www.sgu.ac.id & 17.171 & 5 & 94.733 & 32.067 & 28 & 715 & 733.133 \\
\hline www.ums.ac.id & 7.403 & 5 & 17.267 & 43.133 & 9 & 2732 & 165006.8 \\
\hline www.unsrat.ac.id & 8.469 & 6 & 44.533 & 163.333 & 10 & 1596 & 25213.333 \\
\hline urindo.ac.id & 16.298 & 0 & 12.533 & 56.667 & 18.6 & 1247 & 0 \\
\hline www.usd.ac.id & 9.442 & 6 & 17.867 & 885.333 & 2 & 610.333 & 41795.333 \\
\hline unissula.ac.id & 38.997 & 5 & 23.267 & 99.267 & 13 & 810 & 40449.667 \\
\hline www.upnyk.ac.id & 4.824 & 0 & 2.267 & 190.2 & 13.467 & 816 & 23509.667 \\
\hline www.akakom.ac.id & 4.870 & 3 & 20.667 & 31 & 1.067 & 777 & 15868.867 \\
\hline bobot & 9 & 7 & 1 & 2 & 2 & 3 & 7 \\
\hline
\end{tabular}

TABEL II. Nilai rata-rata dari data $4 I C U$ untuk data Januari 2018

\begin{tabular}{c|c|c|c|c|c|c|c}
\hline \multicolumn{1}{|c|}{ situs } & LT & PR & BL & MV & CV & B & RF \\
\hline ugm.ac.id & 11.747 & 7 & 51.267 & 46.867 & 6 & 20255 & 367405.667 \\
\hline www.ui.ac.id & 11.609 & 7 & 344.267 & 59 & 481.133 & 17799 & 474735.867 \\
\hline www.uny.ac.id & 6.585 & 6 & 94.6 & 38 & 8 & 7678 & 138269.933 \\
\hline ub.ac.id/ & 7.405 & 6 & 44.467 & 93.6 & 5 & 9603 & 96207.8 \\
\hline ipb.ac.id & 23.984 & 6 & 123.867 & 285.4 & 37 & 12828 & 215875.667 \\
\hline www.unja.ac.id & 22.175 & 5 & 38.2 & 133.267 & 76.6 & 758 & 13387 \\
\hline uin-suska.ac.id & 12.441 & 5 & 137.933 & 37.467 & 9 & 1264 & 37015.667 \\
\hline
\end{tabular}




\begin{tabular}{c|c|c|c|c|c|c|c}
\hline www.ubaya.ac.id & 14.961 & 5 & 90.267 & 18.333 & 12 & 768.4 & 13775.2 \\
\hline www.usd.ac.id & 9.442 & 6 & 17.867 & 885.333 & 2 & 610.333 & 41795.333 \\
\hline www.unimed.ac.id & 36.969 & 6 & 98 & 98.733 & 19.467 & 1347.933 & 147537.867 \\
\hline www.unsrat.ac.id & $\mathbf{8 . 4 6 9}$ & $\mathbf{6}$ & $\mathbf{4 4 . 5 3 3}$ & $\mathbf{1 6 3 . 3 3 3}$ & $\mathbf{1 0}$ & $\mathbf{1 5 9 6}$ & $\mathbf{2 5 2 1 3 . 3 3 3}$ \\
\hline unri.ac.id & 19.287 & 6 & 282.067 & 106.4 & 18 & 1376 & 51135.333 \\
\hline www.narotama.ac.id & 4.571 & 5 & 51.6 & 6.333 & 5.333 & 4568 & 34006.267 \\
\hline www.uksw.edu & 5.331 & 5 & 73.067 & 36 & 2.933 & 1090 & 56956.267 \\
\hline undiksha.ac.id & 14.811 & 6 & 376.333 & 50.333 & 29.267 & 987 & 14892.533 \\
\hline www.unpas.ac.id & 19.298 & 5 & 453.067 & 39 & 104 & 750 & 30569.267 \\
\hline bobot & 9 & 7 & 1 & 2 & 2 & 3 & 7 \\
\hline
\end{tabular}

TABEL III. Hasil perhitungan ranking menggunakan metode LWM untuk data webometrics (Januari 2018)

\begin{tabular}{c|c|c|c|c|c|c|c}
\hline Situs & LT & PR & BL & MV & CV & B & RF \\
\hline www.umuslim.ac.id & 0.979 & 0.5 & 0.809 & 1 & 0.78 & 0 & 0.007 \\
\hline www.esaunggul.ac.id & 0.557 & 0.833 & 0.824 & 0.957 & 0 & 1 & 0.44 \\
\hline ipdn.ac.id & 1 & 0.833 & 0.722 & 0.983 & 0.344 & 0.105 & 0.008 \\
\hline www.sgu.ac.id & 0.639 & 0.833 & 0 & 0.986 & 0.784 & 0.083 & 0.004 \\
\hline www.ums.ac.id & 0.925 & 0.833 & 0.838 & 0.973 & 0.937 & 0.908 & 1 \\
\hline www.unsrat.ac.id & $\mathbf{0 . 8 9 3}$ & $\mathbf{1}$ & $\mathbf{0 . 5 4 3}$ & $\mathbf{0 . 8 3 4}$ & $\mathbf{0 . 9 2 8}$ & $\mathbf{0 . 4 4 3}$ & $\mathbf{0 . 1 5 3}$ \\
\hline urindo.ac.id & 0.664 & 0 & 0.889 & 0.957 & 0.86 & 0.3 & 0 \\
\hline www.usd.ac.id & 0.865 & 1 & 0.831 & 0 & 0.993 & 0.04 & 0.253 \\
\hline unissula.ac.id & 0 & 0.833 & 0.773 & 0.908 & 0.904 & 0.122 & 0.245 \\
\hline www.upnyk.ac.id & 1 & 0 & 1 & 0.803 & 0.901 & 0.124 & 0.142 \\
\hline www.akakom.ac.id & 0.999 & 0.5 & 0.801 & 0.987 & 1 & 0.108 & 0.096 \\
\hline
\end{tabular}


TABEL IV. Hasil perhitungan ranking menggunakan metode LWM untuk data 4ICU (Januari 2018)

\begin{tabular}{c|c|c|c|c|c|c|c}
\hline Situs & LT & PR & BL & MV & CV & B & RF \\
\hline www.unja.ac.id & 0.979 & 0.5 & 0.809 & 1 & 0.78 & 0 & 0.007 \\
\hline uin-suska.ac.id & 0.557 & 0.833 & 0.824 & 0.957 & 0 & 1 & 0.44 \\
\hline www.ubaya.ac.id & 1 & 0.833 & 0.722 & 0.983 & 0.344 & 0.105 & 0.008 \\
\hline www.usd.ac.id & 0.639 & 0.833 & 0 & 0.986 & 0.784 & 0.083 & 0.004 \\
\hline www.unimed.ac.id & 0.925 & 0.833 & 0.838 & 0.973 & 0.937 & 0.908 & 1 \\
\hline www.unsrat.ac.id & $\mathbf{0 . 8 9 3}$ & $\mathbf{1}$ & $\mathbf{0 . 5 4 3}$ & $\mathbf{0 . 8 3 4}$ & $\mathbf{0 . 9 2 8}$ & $\mathbf{0 . 4 4 3}$ & $\mathbf{0 . 1 5 3}$ \\
\hline unri.ac.id & 0.664 & 0 & 0.889 & 0.957 & 0.86 & 0.3 & 0 \\
\hline www.narotama.ac.id & 0.865 & 1 & 0.831 & 0 & 0.993 & 0.04 & 0.253 \\
\hline www.uksw.edu & 0 & 0.833 & 0.773 & 0.908 & 0.904 & 0.122 & 0.245 \\
\hline undiksha.ac.id & 1 & 0 & 1 & 0.803 & 0.901 & 0.124 & 0.142 \\
\hline www.unpas.ac.id & 0.999 & 0.5 & 0.801 & 0.987 & 1 & 0.108 & 0.096 \\
\hline
\end{tabular}

